\title{
Urine-based testing for Chlamydia trachomatis among young adults in a population-based survey in Croatia: Feasibility and prevalence
}

\author{
Ivana Božičević ${ }^{*}$, Ivana Grgić ${ }^{2}$ Snježana Židovec-Lepej², Jurja-Ivana Čakalo', Sanja Belak-Kovačević²,
} Aleksandar Štulhofer ${ }^{3}$ and Josip Begovac ${ }^{2}$

\begin{abstract}
Background: We assessed the feasibility of collecting urine samples for testing on genital Chlamydia trachomatis infection in a population-based survey, and prevalence of this infection among young people aged 18-25 in Croatia. In Croatia, as in the other countries of Eastern Europe, there is a lack of data on prevalence of $C$ trachomatis in the general population, including young adults.

Methods: We sampled participants using a nationally representative, multi-stage stratified probability sample of young men and women. Detection of $C$ trachomatis DNA in urine samples was performed by using a real-time PCR assay COBAS ${ }^{\circledR} \operatorname{TaqMan}^{\circledR}$ CT Test, v2.0.

Results: Overall, 1005 young adults participated in the behavioural part of the survey, and $27.9 \%$ men and 37.5\% women who were sexually experienced agreed to provide urine samples for testing on C trachomatis. Using multivariate analysis, women were significantly more likely to provide urine samples than men $(\mathrm{aOR}=1.53,95 \% \mathrm{Cl}$ 1.14-2.06) as were those who reported no condom use at last intercourse (aOR $=1.95,95 \% \mathrm{Cl} 1.44-2.62$ ).

Prevalence of $C$ trachomatis infection among those who were sexually experienced was $7.3 \%$ in men and $5.3 \%$ in women.

Conclusions: Population-based surveys that use probabilistic sampling are a feasible way to obtain population estimates of $C$ trachomatis prevalence among young adults in Croatia, but it is challenging to obtain an adequate response rate. The prevalence of $C$ trachomatis among young adults in Croatia found in this study was higher than that found in other European countries with similar survey response rates.
\end{abstract}

\section{Background}

Chlamydia trachomatis is the most common bacterial sexually transmitted infection (STI) in Croatia. In 2008, 11 cases of Neisseria gonorrhoeae, 31 cases of syphilis and 553 cases of genital $C$ trachomatis infection were reported [1]. However, those figures are based on case reporting, and are believed to substantially underestimate true incidence. $C$ trachomatis case rates in Croatia ranged from $7.04 / 100,000$ in 1999 to $9.11 / 100,000$ in 2007 , compared to $3.99 / 100,000$ to $10.04 / 100,000$ in Slovenia, and $96.32 / 100,000$ to $200.26 / 100,000$ in the

\footnotetext{
* Correspondence: Ivana.Bozicevic@lshtm.ac.uk

'WHO Collaborating Centre for Capacity Development in HIV Surveillance; School of Medicine, Zagreb, Croatia

Full list of author information is available at the end of the article
}

United Kingdom [1]. In Croatia, as in the other countries of Eastern Europe, there is a lack of data on prevalence of $C$ trachomatis in the general population, including young adults [2]. The focus of STI surveillance in Eastern Europe has been mainly on universal case reporting and interpretation of trends in aggregated national rates of STIs: this obfuscates variations in burden of infections among different demographically and behaviourally defined groups in the population. Although compulsory in most countries, reporting of bacterial STIs in Eastern Europe is mostly done by public institutions and tends to be incomplete [3].

The effectiveness of case reporting systems for $C$ trachomatis depends on screening policies and health-seeking behaviour, service utilisation and reporting practices

\section{Ciomed Central}


of STI service providers. Population-based studies on prevalence of curable bacterial STIs, including $C$ trachomatis, are needed to make evidence-based decisions on whom to screen [4]. Such studies have a crucial role in surveillance of STIs as they rely on probability-based sampling techniques, which enables them to obtain robust and comprehensive data on demographic and behavioural risk factors for infections [5].

This study aimed to estimate the HIV and STI-related risk behaviors among young adults aged 18-25 in Croatia in 2010 and to compare these results with the results of a similar survey that was conducted in 2005 [6,7]. In addition, the study assessed the feasibility of collecting urine samples to test for and determine the prevalence of $C$ trachomatis infection. Data on sexual behaviours and comparison with results of the survey carried out in 2005 will be described elsewhere.

\section{Methods \\ Sampling}

This study was carried out in a nationally representative, multi-stage stratified probability sample $(\mathrm{n}=1005)$ of young men and women aged 18-25 years. Similar multistage cluster-based households surveys were used to measure sexual behaviours and $C$ trachmatis prevalence in Great Britain and Slovenia [8,9]. Multi-stage stratified survey design is recommended by the World Health Organization in order to obtain nationally representative estimates of HIV and STIs [10]. The sample size calculation for this cross-sectional survey was based on the $+/-10 \%$ change in condom use at most recent sexual intercourse from the baseline of $55 \%$ observed in the 2005 national probability sample of the same population [6]. As no reliable population-based data existed on the prevalence of $C$ trachomatis among Croatian young adults, this biological indicator was not employed in the sample size calculations.

Data were collected in February and March 2010. We stratified the sample by county, size of settlement $(\leq 2000$ persons; 2001-10 000; $10001-100000$; >100 001), age and sex. We based the sampling frame on the results of the most recent census, which was conducted in 2001. We randomly selected 106 sampling points (settlements) from all 21 counties of Croatia proportional to the population size. Following a detailed procedure for randomised selection of households, 9-10 participants were interviewed at each sampling point. Where there was more than one resident aged 18-25 years in one household, we selected the young adult who had the most recent birthday to participate in the survey.

\section{Questionnaire}

The questionnaire consisted of two parts. A trained interviewer administered the first part face-to-face; this included questions on demographic and socio-economic characteristics of respondents, knowledge and attitudes towards HIV/AIDS, and beliefs about condoms and condom use. The second part of the questionnaire was selfadministered and contained questions related to sexual behaviours and experiences. The questionnaire was modified from the survey conducted in 2005 [6]. We pilot tested this modified questionnaire for comprehensiveness and completion time among 235 students from four metropolitan secondary schools in 2009.

\section{Interviews and specimen collection}

A majority of interviewers were women between 25 and 35 years of age, who had considerable experience in interviewing for one or more national research companies. All interviewers received an additional six hours of training focused on interviewing young adults on sensitive topics and collection of biological samples. All participants were interviewed in their homes, after giving informed consent. Consent for providing urine samples was administered separately at which time information and guidance on how to take urine samples was provided. All individuals who gave urine received an information sheet with a unique sample code and a toll-free number to call for a test result. As no names or other personal identifiers were collected, participants were instructed to call to obtain their test results. All data collection was anonymous and confidential.

Phone control of the field work was carried out by study co-ordinators on $30 \%$ of the households included in the survey. All study procedures were approved by the Ethical Review Board of the Faculty of Humanities and Social Sciences, University of Zagreb and the Ethical Board of the University Hospital for Infectious Diseases "Dr. Fran Mihaljević" in Zagreb.

Detection of $C$ trachomatis DNA in urine samples was performed using a real-time PCR assay COBAS ${ }^{\circledR}$ TaqMan ${ }^{\circledR}$ CT Test, v2.0 (Roche Molecular Systems, Branchburg, NJ, USA). Following manual DNA extraction, we performed real-time PCR using COBAS ${ }^{\circledR}$ TaqMan $^{\circledR} 48$ Analyzer (Roche Molecular Systems, Branchburg, NJ, USA), as recommended by the manufacturer. This realtime PCR assay employs two sets of probes and primers for amplification of two separate target sequences, one for the $C$ trachomatis cryptic plasmid and other for the ompA gene of the $C$ trachomatis chromosome, which ensures the detection of all $C$ trachomatis strains (including the new Swedish variant) [11].

\section{Analyses}

We compared factors associated with providing urine among those who had previousely had sexual intercourse using bivariate and multivariate logistic regression analyses. The following socio-demographic and 
behavioural variables were considered potential correlates with respect to the likelihood of providing urine and the prevalence of $C$ trachomatis infection: gender, self-estimated socio-economic status, living with both parents until 18 years of age, having obtained information on HIV/AIDS at school, age of first sexual intercourse, number of sexual partners in the past 12 months and in the lifetime, use of condoms at last intercourse and ever having a concurrent partnership. Results are presented as odds ratios (ORs) with 95\% confidence intervals $(95 \% \mathrm{CI})$. Variables associated with willingness to provide urine at the level of $p<0.2$ on bivariate analysis were included in the multivariate logistic regression model. The cut-off for considering a result to be statistically significant in the multivariate analysis was set up at $\mathrm{p}=0.05$.

Analysis of data was performed using STATA 8.0 [12]. Participants with missing values were excluded from the analyses. Due to the small number of individuals testing positive for $C$ trachomatis infection, multivariate regression analysis was not conducted and we compared the prevalence of $C$ trachomatis infection across sociodemographic and behavioural variables with chi square tests and Fisher exact tests. Fisher's exact test was used when the expected value in any of the cells of a contingency table was below 5 .

\section{Results}

Overall, 1005 participants completed the questionnaire of whom 510 (50.8\%) were men and 495 (49.3\%) were women. The median age of respondents was 21 (interquartile range, 19-23). Eight hundred sixty-one (86.2\%) participants reported ever having had sexual intercourse. Of these, 280 (32.5\%) agreed to provide urine samples for $C$ trachomatis testing. An additional two respondents' urine samples were inhibited on PCR, three who did not provide sufficient urine for analysis, and one respondent's sample was lost during shipping; we excluded these six from further analysis.

Table 1 shows the proportion of those agreeing to provide urine samples by socio-demographic and behavioural variables. In multivariate analysis, women had a significantly higher likelihood of providing a urine sample compared to men, as did those who did not use condoms at last intercourse.

Prevalence of $C$ trachomatis infection among those who had sexual intercourse $(\mathrm{n}=274)$ was $6.2 \%(95 \%$ CI 3.3\%-9.1\%) (Table 2). We investigated $C$ trachomatis positivity by different determinants, such as gender, socio-economic and behavioural characteristics, but none of these was significantly associated with $C$ trachomatis positivity at $\mathrm{p}<0.05$ level.

Sixty-nine $(23.4 \%)$ participants called to obtain test results, and out of these, only four were diagnosed with
$C$ trachomatis infection. Those positive for infection were asked for their postal addresses when they called to ask for their test results. They were sent the test results by mail, and were instructed to seek treatment from gynaecologists or general practitioners.

\section{Discussion}

This is the first general population-based survey on sexual behaviours in young adults in Croatia that included willingness to test for $C$ trachomatis. The response rate for collecting urine specimens was $32.5 \%$, and the prevalence of $C$ trachomatis infection in sexually active individuals was $7.3 \%$ in men and $5.3 \%$ in women. Women, those who perceived their socio-economic status to be lower than average compared to their peers and those who did not use condoms at last intercourse were more likely to provide urine, possibly indicating an awareness of greater vulnerability towards STIs.

The main limitation in interpretation of determinants for $C$ trachomatis prevalence is a low response rate to urine specimen collection. This could be due to a lack of awareness of young adults of the importance of screening for $C$ trachomatis, or alternatively of inadequate skills of interviewers and operational difficulties in the field implementation of such studies. Urine samples were transported from participants' homes to the Counties Institutes of Public Health (there are 21 counties in Croatia), and from there to the "Dr. Fran Mihaljević" University Hospital for Infectious Diseases in Zagreb. Such operational difficulties in carrying out integrated bio-behavioural surveys of STIs have been described elsewhere [13,14].

The response rate achieved in our survey is similar to that achieved in population-based $C$ trachomatis prevalence assessment surveys that used mail-delivered testing among young adults in Tartu, Estonia (34\%), and the Netherlands $(41 \%)[15,16]$. In Estonia, prevalence of $C$ trachomatis among women and men aged 18-35 years was $6.9 \%$ and $2.7 \%$, respectively [15]. In the Netherlands, the prevalence of $C$ trachomatis infection was $2.5 \%$ in women and $1.5 \%$ in men 15-29 years old [16]. In Eastern Europe, a household-based probability sample survey that estimated prevalence of infection with $C$ trachomatis was carried out in Slovenia in 2001 among 18-49 year olds [8]. It found the prevalence of $C$ trachomatis infection to be $4.1 \%$ among both men and women 18-24 years old, and the response rate to urine specimen collection was $50.9 \%$ among men and $60.0 \%$ among women. In Great Britain, prevalence of $C$ trachomatis infection was $2.7 \%$ among men and 3.0\% among women aged 18-24 in a household-based probability sample survey carried out in 2001 [9].

In the US, a number of household surveys have measured chlamydia prevalence. In three studies carried out 
Table 1 Factors associated with providing urine among those who had sexual intercourse

\begin{tabular}{|c|c|c|c|c|}
\hline & $\begin{array}{l}\text { Provided } \\
\text { urine (\%) }\end{array}$ & Base & $\begin{array}{l}\text { Unadjusted OR } \\
(95 \% \mathrm{Cl})\end{array}$ & $\begin{array}{c}\text { Adjusted OR } \\
(95 \% \mathrm{Cl})\end{array}$ \\
\hline Total & 32.5 & 861 & & \\
\hline Gender & & & $p=0.003$ & $p=0.004$ \\
\hline Male & 27.9 & 445 & 1.0 & 1.0 \\
\hline Female & 37.5 & 416 & $1.55(1.17-2.07)$ & $1.53(1.14-2.06)$ \\
\hline Age & & & $p=0.044$ & $p=0.160$ \\
\hline $18-21$ & 29.0 & 393 & 1.0 & 1.0 \\
\hline $22-25$ & 35.5 & 468 & $1.35(1.00-1.80)$ & $1.24(0.92-1.67)$ \\
\hline Self-estimated socio-economic status & & & $p=0.132$ & $p=0.074$ \\
\hline Better than/equal to the others & 31.9 & 832 & 1.0 & 1.0 \\
\hline Worse than the others & 48.3 & 29 & $1.99(0.94-4.17)$ & $2.01(0.93-4.31)$ \\
\hline Lived with both parents until 18 years of age & & & $p=0.142$ & $p=0.252$ \\
\hline Yes & 31.8 & 746 & 1.0 & 1.0 \\
\hline No & 38.9 & 108 & $1.37(0.90-2.07)$ & $1.29(0.84-1.98)$ \\
\hline Got information about HIV/AIDS at school & & & $p=0.170$ & $p=0.112$ \\
\hline No & 22.5 & 40 & 1.0 & 1.0 \\
\hline Yes & 33.0 & 821 & $1.70(0.80-3.62)$ & $1.88(0.86-4.1)$ \\
\hline Age of first sexual intercourse & & & $p=0.273$ & \\
\hline$\leq 16$ & 30.4 & 306 & 1.0 & \\
\hline$\geq 17$ & 34.1 & 546 & $1.18(0.88-1.60)$ & \\
\hline Number of partners in the past 12 months & & & $p=0.879$ & \\
\hline $0-1$ & 32.2 & 549 & 1.0 & \\
\hline$\geq 2$ & 32.8 & 290 & $1.02(0.76-1.39)$ & \\
\hline Lifetime number of partners & & & $p=0.800$ & \\
\hline $0-1$ & 30.8 & 185 & 1.0 & \\
\hline $2-3$ & 33.2 & 244 & $1.12(0.74-1.68)$ & \\
\hline$\geq 4$ & 33.6 & 393 & $1.14(0.78-1.65)$ & \\
\hline Used condom at last intercourse & & & $p<0.0001$ & $p<0.0001$ \\
\hline Yes & 24.8 & 407 & 1.0 & 1.0 \\
\hline No & 39.4 & 454 & $1.97(1.47-2.64)$ & $1.95(1.44-2.62)$ \\
\hline Concurrent partnerships ever & & & $p=0.373$ & \\
\hline No & 33.5 & 656 & 1.0 & \\
\hline Yes & 30.2 & 199 & $0.86(0.61-1.21)$ & \\
\hline
\end{tabular}

a $\mathrm{OR}=$ odds ratio; $95 \% \mathrm{Cl}=95 \%$ confidence interval

${ }^{\mathrm{b}} \mathrm{p}$-values represent significance test for heterogeneity across the variable

amongst young adults, response rates of $61-81 \%$ were achieved [17-19]. The response rates in the studies carried out in the US are higher than in our study, possibly because of monetary and other incentives (food coupons) given for participating.

Compared to the European surveys that obtained similar response rates, the prevalence of $C$ trachomatis found in this study is considerable, particularly in men. However, as the results suggest, those with higher levels of risk behaviours (not using condoms at last sexual intercourse) were more likely to provide urine samples, hence the prevalence observed in our study is likely to overestimate the true prevalence of $C$ trachomatis in this population. Therefore, the prevalence of $C$ trachomatis found in our study should not be generalized to the population aged 18-25 in Croatia due to greater willingness of those likely to be at higher risk to provide urine and the low response rate. Greater willingness of those with higher sexual risk behaviours to provide urine was also reported in the population-based survey in Great Britain [20].

Although findings were not statistically significant, in our study prevalence of $C$ trachomatis was higher among those socially vulnerable, e.g., those who did not live with their parents up until the age of 18 , unemployed and those with self-perceived lower socio-economic status. These findings provide strong evidence for the implementation of screening policies for $C$ trachomatis in Croatia, and expanding access to STI prevention and control services to those socially and 
Table 2 Prevalence of Chlamydia trachomatis infection by demographic and behavioural variables ${ }^{a}$

\begin{tabular}{|c|c|c|}
\hline & $\%(n)$ & Total number of participants in the subgroup \\
\hline Total among those who had intercourse & $6.2(17)$ & 274 \\
\hline Gender & & $p=0.491$ \\
\hline Male & $7.3(9)$ & 123 \\
\hline Female & $5.3(8)$ & 151 \\
\hline Self-estimated socio-economic status & & $p=0.601^{b}$ \\
\hline Better than/equal to the others & $6.2(16)$ & 260 \\
\hline Worse then the others & $7.1(1)$ & 14 \\
\hline Professional status & & $p=0.207^{b}$ \\
\hline Attending secondary school & $3.5(1)$ & 29 \\
\hline University student & $4.3(4)$ & 94 \\
\hline Employed & $4.6(5)$ & 109 \\
\hline Unemployed & $12.3(7)$ & 57 \\
\hline Living with both parents until 18 years of age & & $p=0.150^{b}$ \\
\hline Yes & $5.2(12)$ & 232 \\
\hline No & $12.2(5)$ & 41 \\
\hline Got information about HIV/AIDS at school & & $p=0.101^{b}$ \\
\hline No & $22.2(2)$ & 9 \\
\hline Yes & $5.7(15)$ & 265 \\
\hline Age of first sexual intercourse & & $p=0.501$ \\
\hline$\leq 16$ & $7.6(7)$ & 92 \\
\hline$\geq 17$ & $5.5(10)$ & 181 \\
\hline Number of partners in the past 12 months & & $p=0.296$ \\
\hline $0-1$ & $5.2(9)$ & 172 \\
\hline$\geq 2$ & $8.5(8)$ & 94 \\
\hline Lifetime number of partners & & $p=0.175^{b}$ \\
\hline $0-1$ & $1.8(1)$ & 56 \\
\hline $2-3$ & $3.9(3)$ & 78 \\
\hline$>4$ & $8.5(11)$ & 130 \\
\hline Used condom at last intercourse & & $p=0.551$ \\
\hline Yes & $5.1(5)$ & 99 \\
\hline No & $6.9(12)$ & 175 \\
\hline Concurrent partnerships ever & & $p=0.543^{b}$ \\
\hline No & $5.6(12)$ & 214 \\
\hline Yes & $8.3(5)$ & 60 \\
\hline
\end{tabular}

${ }^{\mathrm{a} A m o n g}$ those who had sexual intercourse; ${ }^{\mathrm{b}}$ Fisher exact test

behaviourally vulnerable to this infection. Annual screening of all sexually active women younger than 25 years old is recommended in the United States, while in England, the National Chlamydia Screening Programme offers screening to men and women under the age of 25 years, either annually or when they change partners $[21,22]$. Such guidelines or screening programmes for $C$ trachomatis infection do not exist in Croatia.

Only a small proportion of those who gave urine called to obtain their test results. This is in contrast to the results of the bio-behavioural survey among men who have sex with men done at the University Hospital for Infectious Diseases "Dr. Fran Mihaljevic" in Zagreb in 2006 when $78 \%$ of respondents came to collect their test results [23]. This might imply lower awareness among young adults of sexual health issues. Interviewers who also did urine specimen collection in our study reported that the vast majority of young adults whom they interviewed and asked to provide urine had low awareness of $C$ trachomatis infection and were less likely to provide urine when parents were present at the household at the time of interviewing. They also reported that female and younger interviewers were more successful in obtaining urine specimens from respondents than their male and older counterparts.

In south-east Europe in particular, the absence of more comprehensive surveillance and over-reliance on routine case reporting contributes to perceptions that 
STIs are uncommon; this interferes with appropriate policy responses and presents a fundamental drawback in putting STI control higher on public health policy agendas. As mentioned earlier in the paper, $C$ trachomatis case reporting rate in Croatia was 9.11/100,000 in 2007. Given the results of our survey, it appears that $C$ trachomatis case reporting system substantially underestimates the burden of this infection. There is a pressing need to obtain a valid estimate of the burden of STIs, particularly curable bacterial STIs. Such estimates could lead to targeted responses, which would ideally be appropriate for and accessible to those at greatest risk, and likely driving disease transmission. The increased availability of nucleic acid amplification tests should be used to explore opportunistic screening and community-based testing in settings appropriate for young adults. In addition, such population-based surveys should be implemented in countries such as Croatia where STI case reporting systems substantially underestimates the true burden of disease.

In future surveys, efforts should be made to obtain a higher response rate. The bio-behavioural approach may be improved by adequate investments to ensure increased motivation of both interviewers and participants to provide samples and seek test results. In addition, efforts to increase knowledge about the consequences of untreated $\mathrm{C}$ trachomatis infection by carrying out targeted educational interventions might improve the uptake of home-based testing [24]. Raising awareness of STIs among young adults is important in countries like Croatia where systematic education on sexual health in primary and secondary schools in lacking. Small financial incentives for providing specimens in bio-behavioural surveys, in this case urine, might also increase participation rate [25].

\section{Conclusions}

Population surveys that are household-based are a feasible option for obtaining population estimates of $C$ trachomatis prevalence among young adults in Croatia.

In future, such population-based studies should have a large enough sample size to obtain better estimates in subgroups, and investigate further the gender and socioeconomic differentials in prevalence of $C$ trachomatis. In light of the high prevalence of $C$ trachomatis observed in this study, there is a need for greater public health engagement into prevention, screening and diagnosis of this infection in Croatia.

\section{Acknowledgements}

We thank the respondents for taking part in the survey.

The study was supported by grants from the Croatian Ministry for Science, Education and Sports and the UNDP Office in Croatia. Transport of urine specimens from the field to the laboratory was paid by the pharmaceutical company Pliva. Reagents for detection of C trachomatis DNA by real-time PCR were kindly provided by Roche Diagnostics Representative Office, Croatia.

\section{Author details}

${ }^{1}$ WHO Collaborating Centre for Capacity Development in HIV Surveillance; School of Medicine, Zagreb, Croatia. ${ }^{2}$ University Hospital for Infectious Diseases, Zagreb, Croatia. ${ }^{3}$ Faculty of Humanities and Social Sciences, Zagreb, Croatia.

\section{Authors' contributions}

All authors (IB, IG, SZL, JIC, SBK, AS and JB) participated in the planning and conception of the research questions and the study design. IB, AS and JB conceptualised the study design and coordinated the study implementation. IG and SZL did the laboratory analysis of the samples. IB was responsible for analyzing the data. IB drafted the article, and all authors participated in interpreting the data and critically revising the manuscript. All authors read and approved the revised manuscript.

\section{Competing interests}

The authors declare that they have no competing interests.

Received: 15 November 2010 Accepted: 14 April 2011

Published: 14 April 2011

\section{References}

1. Centralized information system for infectious diseases (CISID) database. Kopenhagen: World Health Organization Regional Office for Europe; 2010 [http://data.euro.who.int/CISID/, (last accessed 23-10-2010).

2. Uuskula A, Puur A, Toompere K, DeHovitz J: Trends in the epidemiology of bacterial sexually transmitted infections in Eastern Europe, 1995-2005. Sex Transm Infect 2010, 86:6-14.

3. Domeika M, Hallen A, Karabanov L, Chudomirova K, Gruber F, Unzeitig V, Pöder A, Deak J, Jakobsone I, Lapinskaite G, Dajek Z, Akovbian V, Gomberg M, Khryanin A, Savitcheva A, Takac I, Glazkova L, Vinograd N, Nedeljkovic M: Chlamydia trachomatis infections in eastern Europe: legal aspects, epidemiology, diagnosis, and treatment. Sex Transm Infect 2002, 78:115-9.

4. Kohl KS, Markowitz LE, Koumans EH: Developments in the screening for Chlamydia trachomatis: a review. Obstet Gynecol Clin North Am 2003, 30:637-58.

5. Wellings $\mathrm{K}$, Cleland J: Surveys on sexual health: recent developments and future directions. Sex Transm Infect 2001, 77:238-41.

6. Stulhofer A, Graham C, Bozicevic I, Kufrin K, Ajdukovic : The assessment of HIV/STI vulnerability and related sexual risk-taking in a nationally representative sample of young Croatian adults. Arch Sex Behav 2007, 36:477-507.

7. Bozicevic I, Stulhofer A, Ajdukovic D, Kufrin K: Patterns of sexual behaviour and reported symptoms of STI/RTIs among young people in Croatiaimplications for interventions' planning. Coll Antropol 2006, 30(Suppl 2):63-70.

8. Klavs I, Rodrigues LC, Wellings K, Kese D, Hayes R: Prevalence of genital Chlamydia trachomatis infection in the general population of Slovenia: serious gaps in control. Sex Transm Infect 2004, 80:121-3.

9. Fenton KA, Korovessis $C$, Johnson AM, McCadden A, McManus $S$, Wellings K, Mercer CH, Carder C, Copas AJ, Nanchahal K, Macdowall W, Ridgway G, Field J, Erens B: Sexual behaviour in Britain: reported sexually transmitted infections and prevalent genital Chlamydia trachomatis infection. Lancet 2001, 358:1851-4.

10. UNAIDS/WHO working group on global HIV/AIDS and STI surveillance: Guidelines for measuring national HIV prevalence in population-based surveys Geneva; 2004.

11. Møller JK, Pedersen LN, Persson K: Comparison of the Abbott RealTime CT new formulation assay with two other commercial assays for detection of wild-type and new variant strains of Chlamydia trachomatis. J Clin Microbiol 2010, 48:440-3.

12. STATA Statistical Software: Release 8.0 STATA Corporation: College Station, TX; 2003.

13. $\mathrm{Ku} \mathrm{L}$, Sonenstein FL, Turner CF, Aral SO, Black CM: The promise of integrated representative surveys about sexually transmitted diseases and behavior. Sex Transm Dis 1997, 24:299-309. 
14. Eggleston $E_{\text {, Turner }}$, Rogers $S$, Roman A, Miller W, Villarroel $M$, Ganapathi L: Monitoring STI prevalence using telephone surveys and mailed urine specimens: a pilot test. Sex Transm Infect 2005, 81:236-8.

15. Uusküla A, Kals M, Denks K, Nurm U, Kasesalu L, Dehovitz J, McNutt LA: The prevalence of chlamydial infection in Estonia: a population-based survey. Int J STD AIDS 2008, 19:455-8.

16. van Bergen J, Götz H, Richardus JH, Hoebe C, Broer J, Coenen T, PILOT CT Study Group: Prevalence of urogenital Chlamydia trachomatis infections in the Netherlands suggests selective screening approaches. Results from the PILOT CT Population Study. Drugs Today 2006, 42(Suppl A):25-33.

17. Klausner JD, McFarland W, Bolan G, Hernandez MT, Molitor F, Lemp GF, Cahoon-Young B, Morrow S, Ruiz J, Young Women's Survey Team: Knockknock: a population-based survey of risk behavior, health care access, and Chlamydia trachomatis infection among low-income women in the San Francisco Bay area. J Infect Dis 2001, 183:1087-92.

18. Ku L, St Louis M, Farshy C, Aral S, Turner CF, Lindberg LD, Sonenstein F: Risk behaviors, medical care, and chlamydial infection among young men in the United States. Am J Public Health 2002, 92:1140-3.

19. Turner CF, Rogers SM, Miller HG, Miller WC, Gribble JN, Chromy JR, Leone PA, Cooley PC, Quinn TC, Zenilman JM: Untreated gonococcal and chlamydial infection in a probability sample of adults. JAMA 2002, 287:726-33.

20. McCadden A, Fenton KA, McManus S, Mercer CH, Erens B, Carder C, Ridgway G, Macdowall W, Nanchahal K, Byron CL, Copas A, Wellings K, Johnson AM: Chlamydia trachomatis testing in the second British National Survey of Sexual Attitudes and Lifestyles: Respondent uptake and treatment outcomes. Sex Transm Dis 2005, 32:387-94.

21. Centers for Disease Control and Prevention: Sexually transmitted diseases treatment guidelines. MMWR 2006, 55:RR-11.

22. Randall S, LaMontagne DS: Screening for chlamydia: seize the day. J Fam Plann Reprod Health Care 2005, 31:98-100.

23. Bozicevic I, Rode OD, Lepej SZ, Johnston LG, Stulhofer A, Dominkovic Z, Bacak V, Lukas D, Begovac J: Prevalence of sexually transmitted infections among men who have sex with men in Zagreb, Croatia. AIDS Behav 2009, 13:303-9.

24. Sacks-Davis R, Gold J, Aitken CK, Hellard ME: Home-based chlamydia testing of young people attending a music festival-who will pee and post? BMC Public Health 2010, 10:376.

25. Currie MJ, Schmidt M, Davis BK, Baynes AM, O'Keefe EJ, Bavinton TP, McNiven M, Martin SJ: 'Show me the money': financial incentives increase chlamydia screening rates among tertiary students: a pilot study. Sex Health 2010, 7:60-5.

Pre-publication history

The pre-publication history for this paper can be accessed here: http://www.biomedcentral.com/1471-2458/11/230/prepub

doi:10.1186/1471-2458-11-230

Cite this article as: Božičević et al: Urine-based testing for Chlamydia trachomatis among young adults in a population-based survey in Croatia: Feasibility and prevalence. BMC Public Health 2011 11:230.

\section{Submit your next manuscript to BioMed Central and take full advantage of:}

- Convenient online submission

- Thorough peer review

- No space constraints or color figure charges

- Immediate publication on acceptance

- Inclusion in PubMed, CAS, Scopus and Google Scholar

- Research which is freely available for redistribution

Submit your manuscript at www.biomedcentral.com/submit
Biomed Central 